

\section{DISCLAIMER}

This report was prepared as an account of work sponsored by an agency of the United States Government. Neither the United States Government nor any agency Thereof, nor any of their employees, makes any warranty, express or implied, or assumes any legal liability or responsibility for the accuracy, completeness, or usefulness of any information, apparatus, product, or process disclosed, or represents that its use would not infringe privately owned rights. Reference herein to any specific commercial product, process, or service by trade name, trademark, manufacturer, or otherwise does not necessarily constitute or imply its endorsement, recommendation, or favoring by the United States Government or any agency thereof. The views and opinions of authors expressed herein do not necessarily state or reflect those of the United States Government or any agency thereof. 


\section{DISCLAIMER}

Portions of this document may be illegible in electronic image products. Images are produced from the best available original document. 
This report was prepared as an account of work sponsored by the United States Government. Neither the United States nor the United States Department of Energy, nor any of their employees, nor any of their contractors, subcontractors, or their employees, makes any warranty, express or implied, or assumes any legal liability or responsibility for the accuracy, completeness or usefulness of any in-

formation, apparatus, product or process disclosed, or represents that its use would not infringe privately owned rights.

\section{PRINTED IN THE UNITED STATES OF AMERICA}

Available from

National Technical Information Service

U. S. Department of Commerce 5285 Port Royal Road

Springfield, Virginia 22161

Price: Printed Copy $\$ 4.00$; Microfiche $\$ 3.00$ 


\title{
Tritium Half-Life
}

\author{
C. R. Rudy and K. C. Jordan
}

Issued: December 22, 1977

\section{MOUND FACILITY}

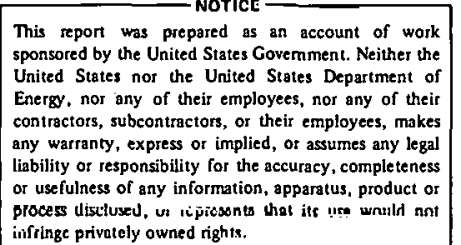

Miamisburg. Dhio 45342

operated by

MONSANTO RESEARCH CORPORATION

a subsidiary of Monsento Company

for the

\section{U. S. DEPARTMENT OF ENERGY}

Contract No. EY-76-C-04-0053 


\section{Summary}

Least squares analyses of calorimetric measurements made at Mound Laboratory on two tritide compounds over a period of $18 \mathrm{yr}$ were performed to determine the half-life of tritium. A half-life of $12.3232 \pm$ 0.0043 mean solar years was obtained.

\section{Introduction}

Previously published [1] and unpublished $[2,3,4]$ reports have indicated a systematically decreasing calculated halflife for tritium resulting from analysis of calorimetric data collected at Mound Laboratory. As newer data had been analyzed, it was found that the fitted halflife decreased from $12.346 \mathrm{yr}$ in 1967 [1] to $12.323 \mathrm{yr}$ in 1976 [4]. In this report, we show that the source of this decrease is due to parts of the data that do not support the hypothesis of one-component decay. Inclusion of these parts of the data in a one-exponential fitting routine led to a constantly decreasing half-life as newer data were collected. In this paper, we report the results of analysis of data collected from september 1959 through May 1977 (1353 measurements). From this analysis we recommend a tritium halflive of $12.3232 \pm 0.0043$ mean solar years.

\section{Data}

The time span and frequency of measurements analyzed in this report are shown in Figure 1. Every power measurement is plotted on this computer-generated graph. (Most of the symbols on this graph are the result of many measurements taken over time spans of tens of days.) Power outputs of two different samples, each a solid tritide compound of differing chemical composition, were measured with five twin-bridge calorimeters $(39,90,91,116,127)$. The chemical composition and initial power of these two samples are listed in Table 1.
The number of measurements, time spans, and standard deviation of a single measurement for different sample-calorimeter pairs are listed in Table 2 . The standard deviations were estimated by $\left[\sum_{1} \mathrm{~d}_{1}{ }^{2} / 2 \mathrm{~N}\right]^{\frac{1}{2}}$ where $d$ is the difference between measurements taken on the same day or on contiguous days and $\mathrm{N}$ is the number of pairs of measurements. For the latter case, a correction was made for the day-to-day decay of the sample. All power measurements were decayed to a common time of the day.

\section{Calculations}

If tritium decay is the only source of heat within a calorimeter, then the data should indicate a single component exponential drop in power output. In fitting the data, we assume that:

$$
Y_{1}=\mathrm{Ae}^{-\lambda t_{1}}+\varepsilon_{1}, i=1, \mathrm{n}: \mathrm{n}=
$$

where $y_{1}$ is the observed power output, $t$ the measurement time, $A$ and $\lambda$ are constants to be fit, and $E_{1}$ the exponential error. We have used an iterative least squares fitting program, CLSQ [5], to estimate the parameters $A$. and $\lambda$, and thus the half-life of tritium ( $\lambda$, the decay constant $=$ In 2/half-life). This FORTRAN program compares the decay constants calculated by successive solutions of the n-simultaneous equations until there is no significant difference between the decay constants. The calculations were performed on a CDC-6600 computer with approximately 14-place precision. 


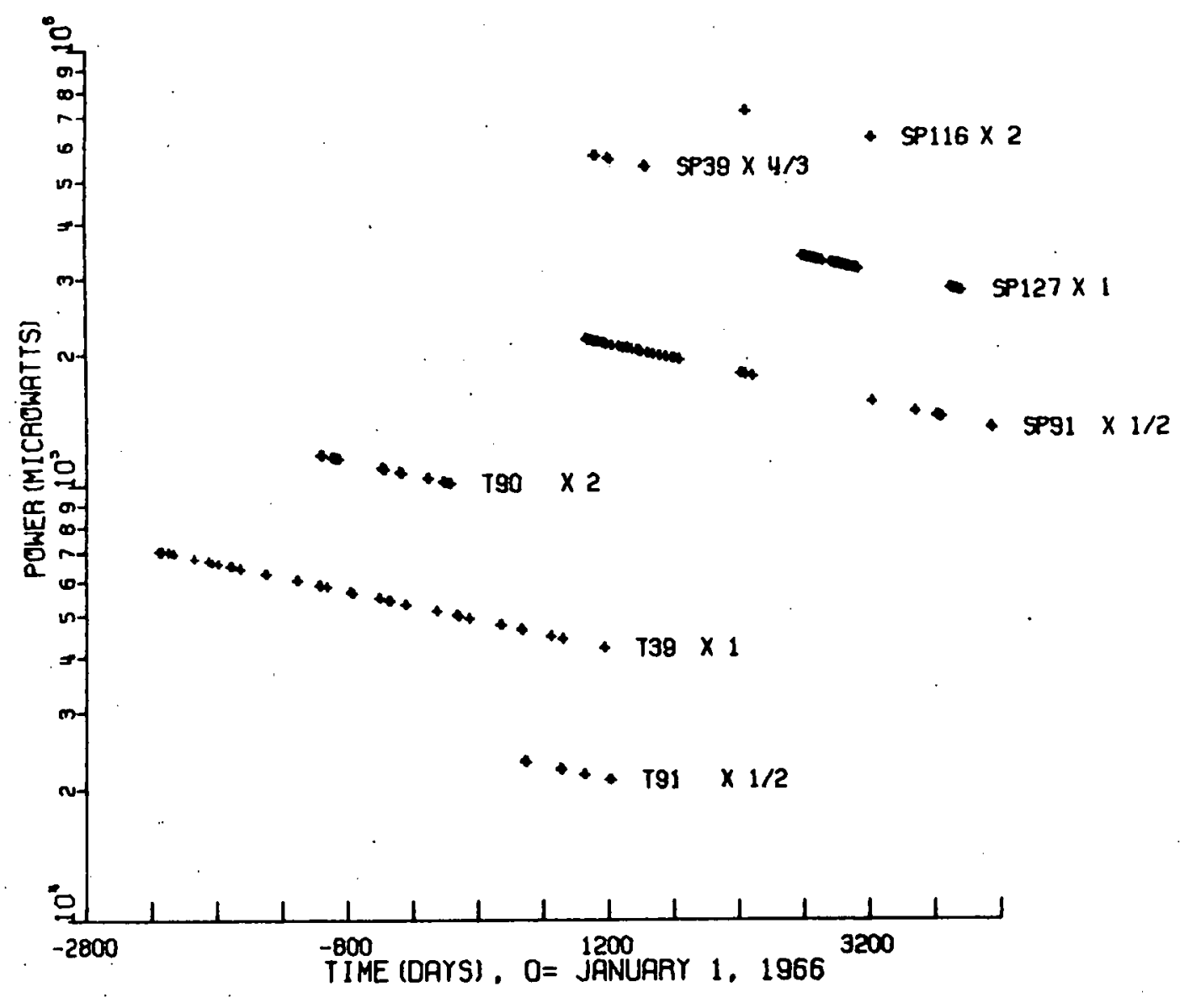

FIGURE 1 - Power measurements for different sample calorimeter pairs.

Table 1 - SAMPLE INFORMATION-

\begin{tabular}{|ccc|}
\hline & Table 1 - SAMPLE INFORMATION- & $\begin{array}{c}\text { Initial } \\
\text { Power } \\
\text { Sample Label }\end{array}$ \\
\hline T & \multicolumn{1}{c}{ Compound } & 0.073 \\
SP & Titanium Tritide & 0.427 \\
& Metal Tritide & \\
\hline
\end{tabular}




\begin{tabular}{|c|c|c|c|c|c|}
\hline Sample & Calorimeter & $\begin{array}{c}\text { Time Span } \\
(\mathrm{y} r)\end{array}$ & $\begin{array}{c}\text { Number of } \\
\text { Measurements }\end{array}$ & $\begin{array}{l}\text { Precision }{ }^{\mathrm{a}} \\
(\mu \mathrm{W})\end{array}$ & $\begin{array}{l}\text { Average } \\
\text { Relative } \\
\text { Precision } \\
\quad(8) \\
\end{array}$ \\
\hline SP & $\begin{array}{c}127^{\circ} \\
127^{\circ} \\
91^{d} \\
39 \\
116\end{array}$ & $\begin{array}{l}1.18 \\
0.28 \\
8.50 \\
1.11 \\
2.64\end{array}$ & $\begin{array}{r}665 \\
141 \\
286 \\
24 \\
23\end{array}$ & $\begin{array}{r}1.1 \\
1.1 \\
3.7 \\
10.2 \\
5.9\end{array}$ & $\begin{array}{l}0.0003 \\
0.0004 \\
0.0010 \\
0.0032 \\
0.0016\end{array}$ \\
\hline $\mathrm{T}$ & $\begin{array}{l}39^{\circ} \\
90^{\circ} \\
91^{\circ}\end{array}$ & $\begin{array}{l}9.81 \\
2.75 \\
1.80\end{array}$ & $\begin{array}{l}84 \\
97 \\
33\end{array}$ & $\begin{array}{l}7.5 \\
7.5 \\
2.2\end{array}$ & $\begin{array}{l}0.0100 \\
0.0139 \\
0.0050\end{array}$ \\
\hline
\end{tabular}

${ }^{a}$ Within-day precision. One standard deviation.

Extensive modifications were performed on calorimeter 127 before this set of measurements. Subsequent measurements on it indicated a shift in the total power. Therefore, this data set was analyzed as a new run.

${ }^{c}$ Earlier parts of this data used in reference [1].

dEarlier parts of this data used in calculating the half-lives quoted in references $[2,3 ; 4]$.

Before accepting the hypothesis of oneexponential decay, one must examine a fit to determine whether such a decay curve satisfactorily explains the data. For a half-life to be acceptable, the calculated curve should fit the data such that the differences between the calculated curve and observed data should be randomly distributed about zero. Any tendency for the data to diverge in a systematic manner can be ascertained by examination of a plot of the residuals, Yobs-Ycalc. Such a plot is shown for various calorimeter runs in Figure 2-5. The half-lives used for $y$ are listed in Table 3. In Figure 2 it can be seen that runs T39 and SP91 diverge from one-exponential decay for earlier measurements. Thus, a one-exponential decay connot be used to fit all of the data for these two runs. The residuals for both of these runs indicate that the observed powers for the earlier measurements are too low to fit a one-exponential decay satisfactorily. This unexplained deficit in the power in the earlier measurements led to a longer fitted half-life that constantly decreased as later data were collected.

Rather than guess the correct extra functional form to fit the data during these earlier measurements or to discard the data of these long runs, we decided to exclude the earlier measurements and fit the remainder of the data with a one-exponential curve. The fitted half-life drops from $12.3315 \mathrm{yr}$ to $12.3253 \mathrm{yr}$ for $\mathrm{T} 39$ and from $12.3261 \mathrm{yr}$ to $12.3235 \mathrm{yr}$ for sp91, after the truncation of earlier data from these runs. The residuals of the modified data are shown in Figure 3 .

We can see from examination of Figure 3 that a one-exponential decay function fits these data much better. The residuals appear to be randomly distributed about 
Table 3 - RESULTS OF ONE-COMPONENT FITS TO TRITIDE CALORIMETER DATA

\begin{tabular}{|c|c|c|c|c|c|c|}
\hline Sample & Calorimeter & $\begin{array}{c}\text { Half-life } \\
\text { (yr) }\end{array}$ & $\begin{array}{r}\text { Standard } \\
\text { deviation } \\
(y r)\end{array}$ & $x_{v}^{2}$ & $\begin{array}{c}\text { Degrees of } \\
\text { freedom }\end{array}$ & $x_{0,0.001}^{2}$ \\
\hline sp & $\begin{array}{r}127 \\
127 \\
91 \\
39 \\
116\end{array}$ & $\begin{array}{l}12.3228 \\
12.3220 \\
12.3235 \\
12.3220 \\
12.3222\end{array}$ & $\begin{array}{l}0.00012 \\
0.0016 \\
0.00011 \\
0.0066 \\
0.00064\end{array}$ & $\begin{array}{l}1.07 \\
0.79 \\
1.56 \\
.8 .18 \\
0.83\end{array}$ & $\begin{array}{r}663 \\
139 \\
182 \\
22 \\
21\end{array}$ & $\begin{array}{l}1.36 \\
1.41 \\
1.36 \\
2.19 \\
2.23\end{array}$ \\
\hline $\mathrm{T}$ & $\begin{array}{l}39 \\
90 \\
91\end{array}$ & $\begin{array}{l}12.3253 \\
12.3280 \\
12.3221\end{array}$ & $\begin{array}{l}0.0028 \\
0.0045 \\
0.0048\end{array}$ & $\begin{array}{l}2.03 \\
1.69 \\
2.66\end{array}$ & $\begin{array}{l}59 \\
95 \\
31\end{array}$ & $\begin{array}{l}1.66 \\
1.50 \\
1.97\end{array}$ \\
\hline
\end{tabular}

Standard deviation of fit scaled by $x_{v}$, if $x_{v}^{2}>x_{v, 0.001}^{2}$.

If estimate of precision and one-exponential hypothesis is correct then the statistic $x_{v}^{2}$ will exceed $x_{v}^{2}>x_{v, 0.001}^{2}$ one time out of one thousand.

Truncated data set. Twenty-three data points for T39 and 102 for SP9I were not used in the calculations. The resultant decrease in fitted time spans is $2.7 \mathrm{yr}$ and $1.3 \mathrm{yr}$, respectively. From the complete data sets we get $12.3315 \mathrm{yr}$ for $\mathrm{T} 39$ and $12.3261 \mathrm{yr}$ for SP91.

a mean of zero although there is some correlation between neighboring measurements. The residuals of other calorimeter runs are shown in Figures 4 and 5 . No systematic deviation seems to be affecting these other runs as was observed for T39 and Sp91, but longer-term variability does seem to be affecting all the data. There appears to be a correlation between residuals of power measurements made at nearly the same time; thus residuals of contiguous measurements have the same sign. This serial correlation is present in all the data collected and is particularly evident in an examination of the residuals of T90. The size of the deviation can be put on a quantitative basis by examination of the statistic $x_{v}^{2} \cdot\left[x_{v}^{2}=(\text { Residuals) })^{2} /(\right.$ variance $x$ degrees of freedom).] For a good fit $x_{v}^{2}$ shnuld be about 1.0 . The calculated values of $\chi_{v}^{2}$ using the within-day estimate of the precision are listed in Table 3. Also listed are the upper limits for $x_{v}^{2}$ that will be exceeded only one time out of one thousand for a true exponential decay for a proper estimate of the precision of the measurements. We see that almost all the fits exceed this upper confidence limit and either the one-exponential hypothesis is wrong or we have underestimated the random error of measurement. We have assumed the latter case as the most probable cause of the large values of $x_{v}^{2}$. We have also assumed that there is a variability greater than our within-day estimate affecting the measurements, that it is normally distributed, and that the measurement variance is larger by $x_{v}^{2}$. The effect of using this larger random error was to increase the variance in half-life by the same factor. Thus if $x_{v}^{2}$ was greater than $x_{v, 0.001}^{2}$ then 
the half-life standard deviation was increased by a factor of $x_{v}$. No such correction is needed for the SP127 runs, which give the best fits of all the data sets. The resultant estimated standard deviations in half-life are listed in Table 3 .

From the fitted half-lives and standard deviations for tritium, we see that two runs, SP9I and SP127, have standard deviations smaller by at least one order of magnitude for most of the other runs. This difference is because of the long time span for the SP9l measurements and the higher precision of the SP127 measurements. If we calculate an average tritium halflife weighted by the inverse of the variance for all of the runs, we get the same result to six significant figures by using only the weighted mean of SP127 and SP91 - $12.3232 \mathrm{yr}$.

The half-lives for SP127 and SP91 differ by only $0.007 \mathrm{yr}$, but the difference is outside the confidençe limits assigned to each value. In order to assign confidence limits, we assume that these two runs represent two independent determinations with one degree of freedom and assign $95 \%$ confidence limits of

$$
\pm t_{v}=1,0.025 \mathrm{~s} / \sqrt{2}= \pm 0.0043 \mathrm{yr} .
$$

The recommended half-life of tritium with 95\% confidence limits, is

$$
12.3232 \pm 0.0043 \text { mean solar yr. }
$$

From examination of Table 3, we see that the confidence intervals for all of the runs overlap this confidence interval.

\section{Discussion}

To conveniently obtain enough power to measure the half-life of tritium accurately, it was necessary to use metal tritide compounds that concentrate the tritium in a small volume to give sufficient power for accurate calorimetric measurement. In addition to the heat produced by the decay of tritium, it is probable that some heat was generated or absorbed from chemical rearrangement of the matrix material. A chemical reaction or phase change generating, for example, $5 \mathrm{kcal}$ of heat over a 10-yr period, would add an average power of $70 \mu \mathrm{w}$ to the measurements, a power easily discernible with the calorimeters used here. In equating the power decay curve to the halflife of tritium, we are assuming that the power generated or absorbed by any chemical rearrangement is in equilibrium with the tritium power. Any change in the rate of rearrangement could perturb the total power curve and lead to a decay curve differing from a one-exponential form. Such a change could be the cause of the deviations obsorved in the earlier measureluents of runs T39 and SP91. These deviations were seen only during the earliest measurements of these samples by all of the calorimeters.

The agreement between all of the calculated half-lives along with the absence of any year-to-year fluctuations for the past $7 \mathrm{yr}$. in the residuals for the two most precise estimates of the half-life (runs SP9I and SP127) support the assumption of one-exponential decay for the data used in calculating the tritium half-life. Other measurements of tritium half-life have been made, the most precise by Jones [6]. Our value of $12.3232 \pm 0.0043 \mathrm{yr}$ is in closer agreement with Jones's value of $12.262 \pm$ $0.004 \mathrm{yr}$ than the calorimeter value reported in 1967 [1], but the difference is still significant. 


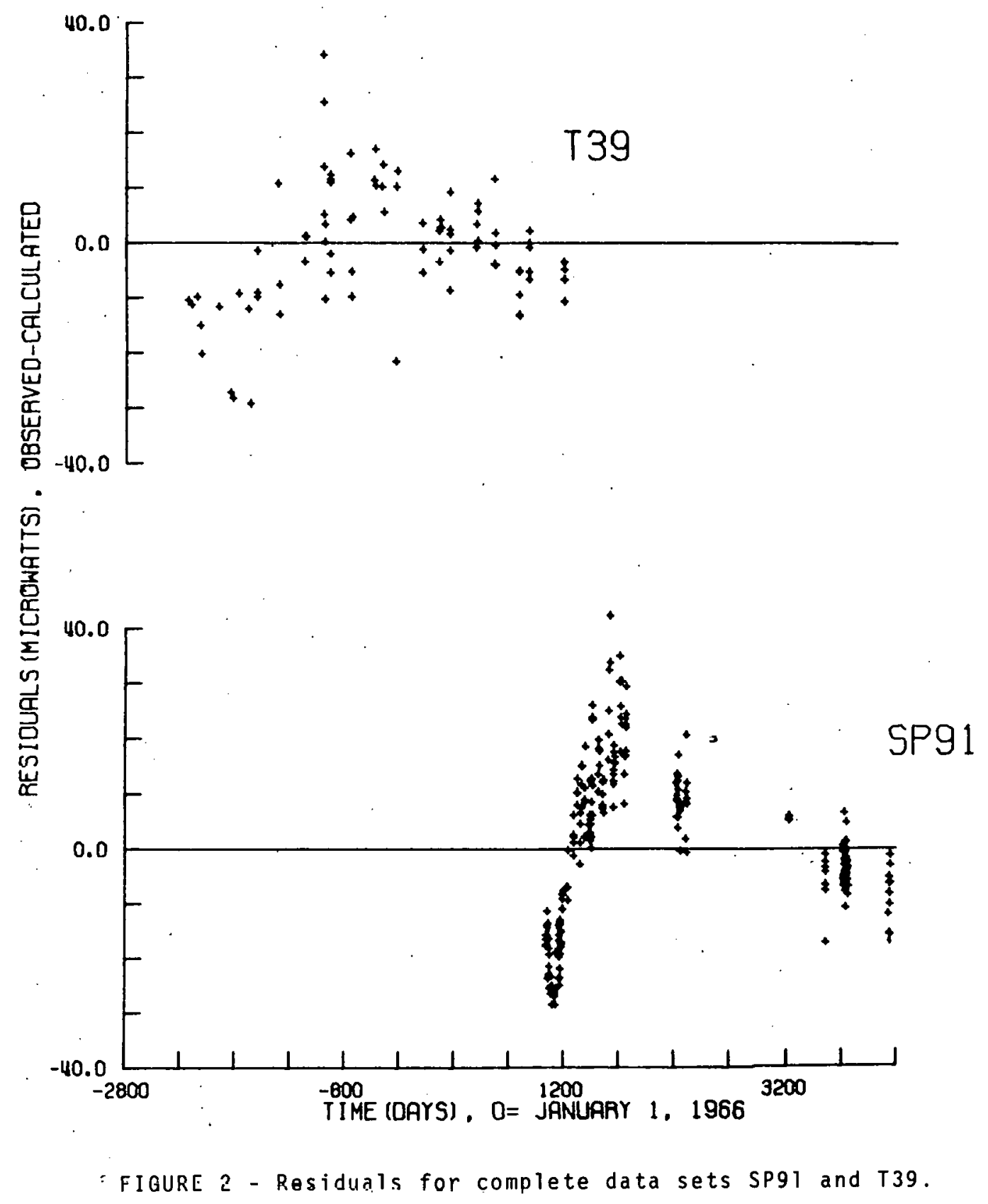

L. 


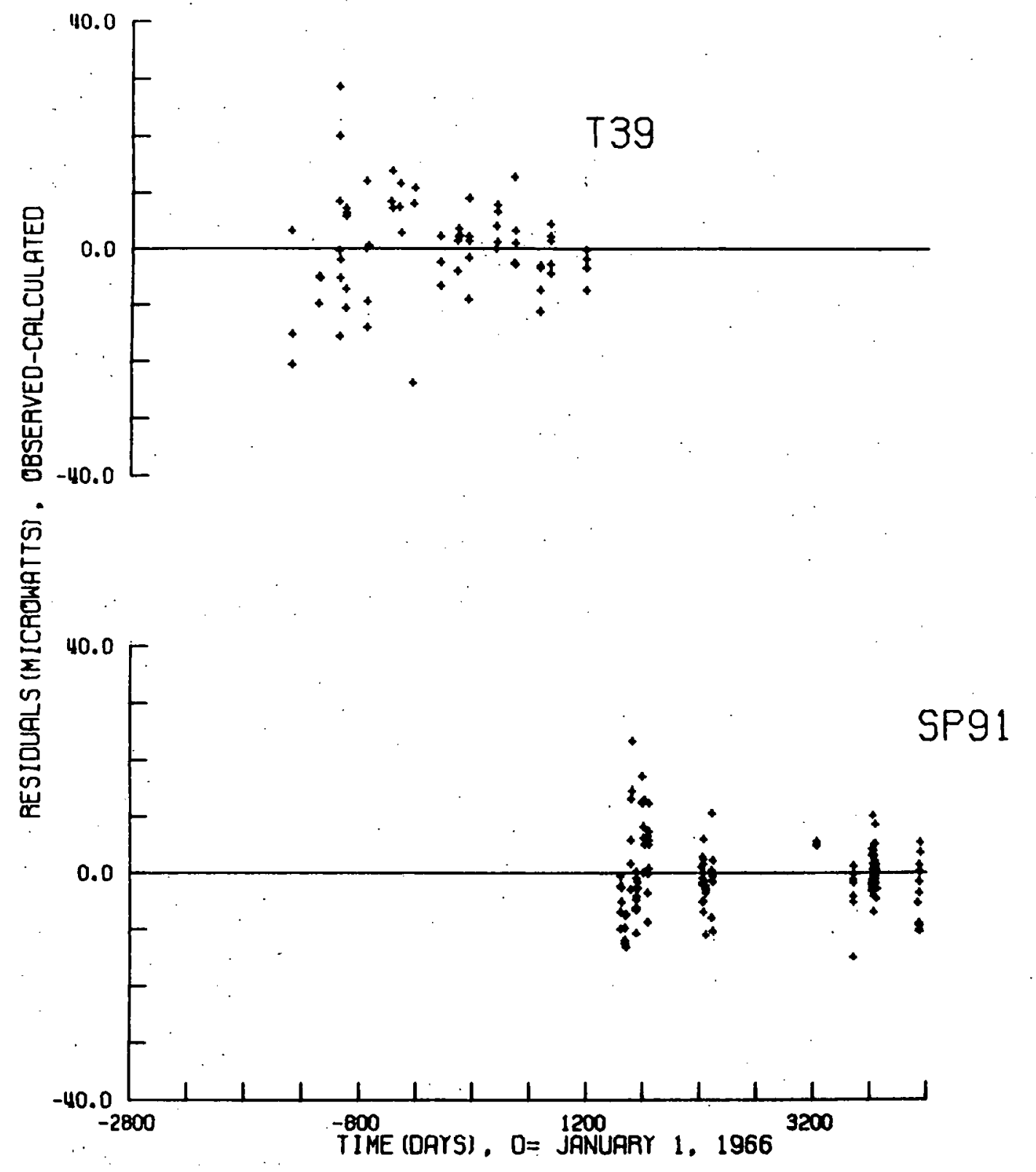

FIGURE 3 - Residuals for truncated data sets SP9l and T39. 


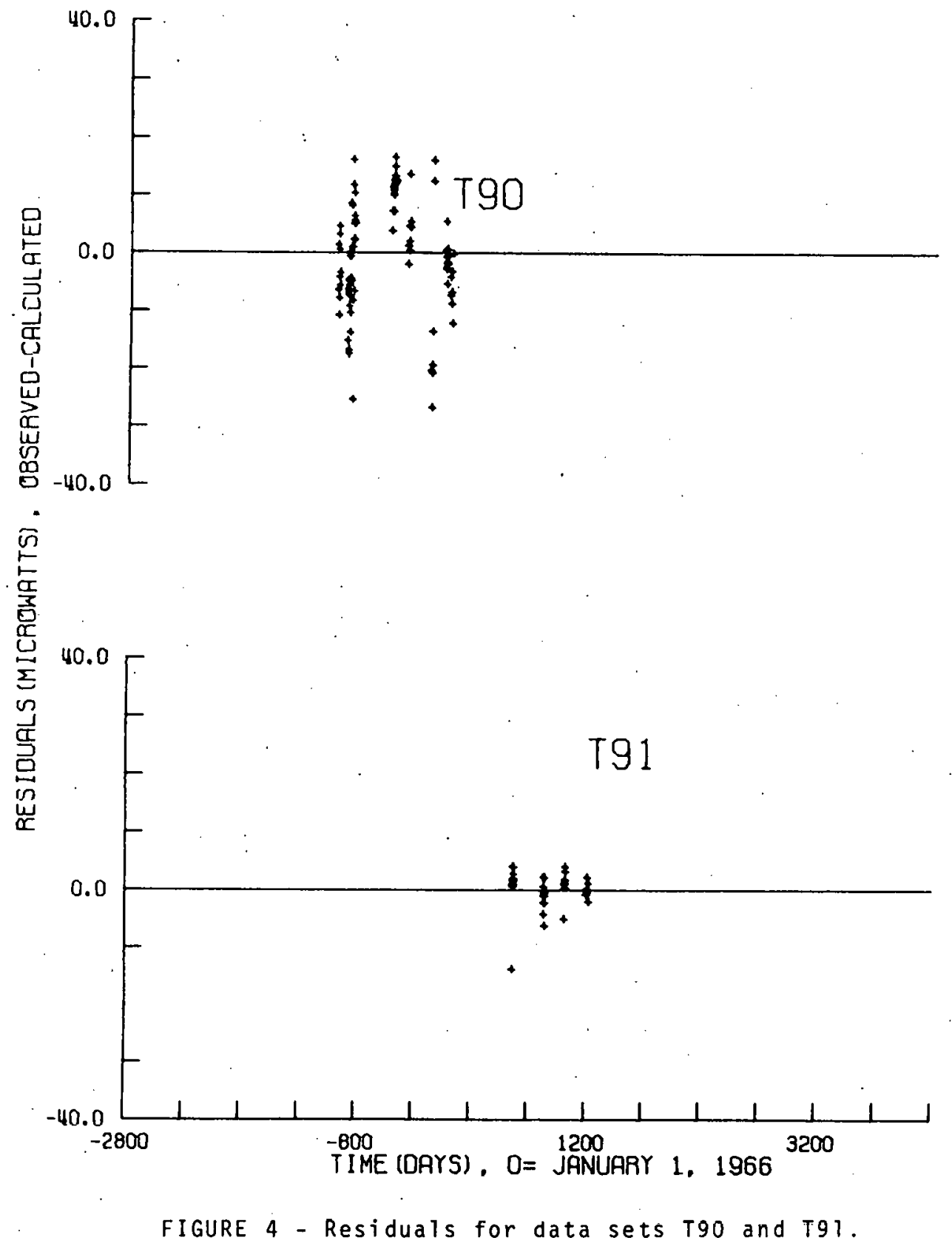




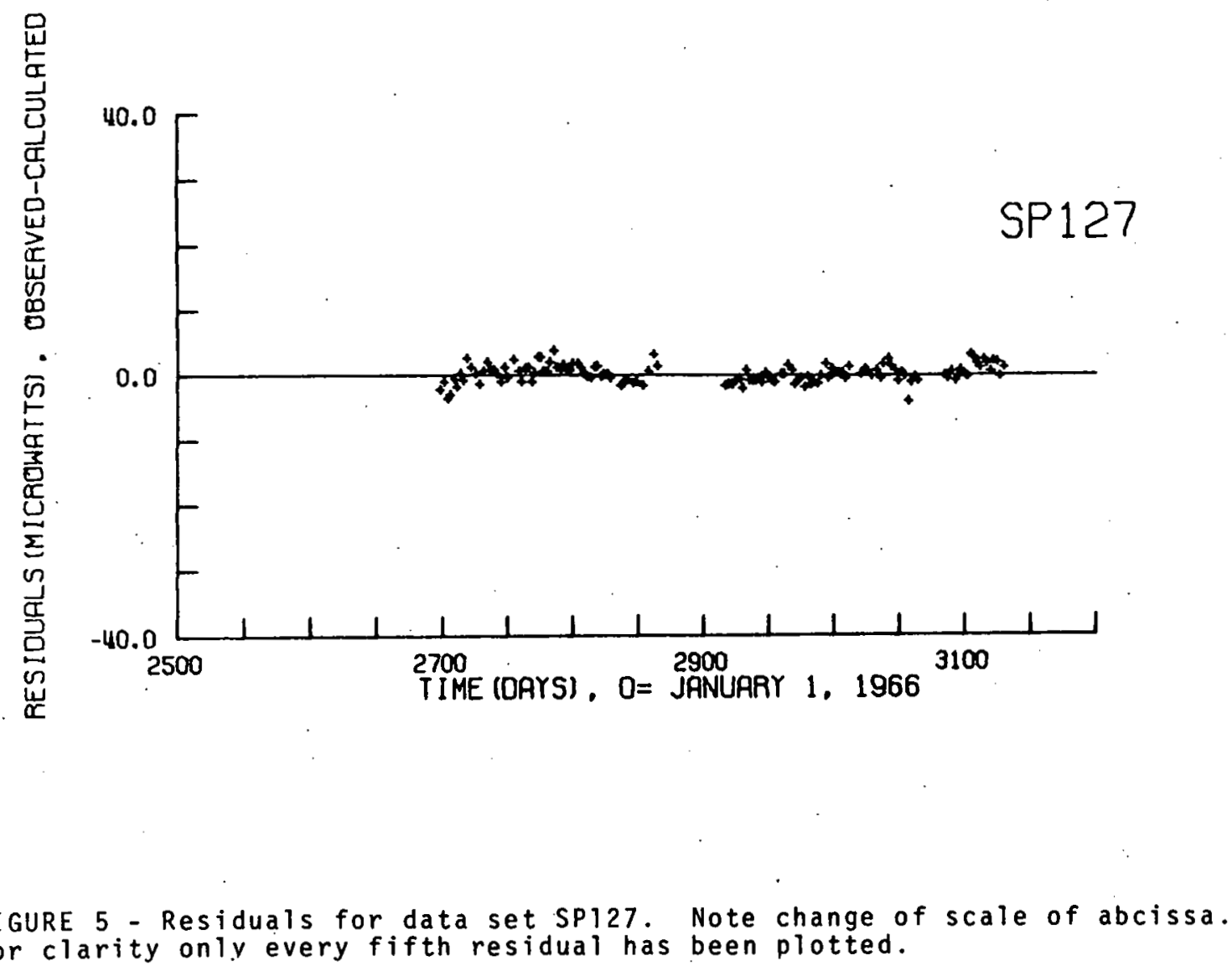

\section{References}

1. K. C. Jordan, et al, J. Inorg. Nucl. 'Chem.' 29, 2129 (1967).

2. S. C. Keeton "Recommended Values for the Tritium Half-Life and Watts per Gram Number," SCL-SM-720230, Sandia Corporation, Livermore, March (1972).

3. S. Sher, "Half-Lives of ${ }^{3} \mathrm{H}$ and ${ }^{238} \mathrm{Pu}, "$ BNL-50233, Brookhaven National Laboratory (1970).
4. K. W. MacMurdo, Private Communication (1976).

5. J. B. Cumming, "CLSQ, the Brookhaven Decay Curve Analysis program, in Applications of Computers to Nuclear Radiochemistry," NAS-NS-3107, National Research Council (1962), p. 25.

6. W. M. Jones, Phys. Rev., 100, 124 (1955). 


\title{
Distribution
}

\author{
EXTERNAL
}

TIC, UC-4 (185)

Monsanto Library, St. Louis

J. A. Chacon, DAO

R. K. Flitcraft, MRC

\section{INTERNAL}

W. T. Cave

C. L. Fellers

C. W. Huntington

L. V. Jones

K. C. Jordan

B. R. Kokenge

$\mathrm{J}$. R. Mcclain

C. R. Rudy

P. W. Seabaugh

W. Smith

D. R. Spangler

W. W. strohm

R. E. Vallee

H. A. Woltermann

Library (15)

Publications (10) 